\title{
Hybrid Task Design: Connecting Learning Opportunities Related to Critical Thinking and Statistical Thinking
}

\author{
Sebastian Kuntze*, Einav Aizikovitsh-Udi**, \& David Clarke*** \\ *Ludwigsburg University of Education, Germany; **Weizman Institute/Beit Berl Academic College, \\ Israel; *** Melbourne University, Australia
}

\section{Abstract:}

Stimulating thinking related to mathematical content is the focus of many tasks in the mathematics classroom. Beyond such content-related thinking, promoting forms of higher order thinking is among the goals of mathematics instruction as well. So-called hybrid tasks focus on combining both goals: they aim at fostering mathematical thinking and higher order thinking through the same mathematical activities-an aim which requires empirical examination. For empirically valid hybrid task design, evidence is required about the nature of the interrelatedness of content-related and higher order thinking. In this article, we choose the example of statistical thinking and critical thinking for exploring the interrelatedness of these different modes of thinking when solving hybrid tasks. Even if theories about statistical thinking and critical thinking have so far followed almost separate strands, there are commonalities at the theoretical level, which facilitate hybrid task design. We report an empirical study, in which a bottom-up analysis of thinking-aloud interviews with adult learners around solution processes of hybrid tasks affords insight into how these modes of thinking may interact when solving such tasks. The results show that the tasks did evoke both statistical thinking and critical thinking: Both modes of thinking entered in an interplay in which we observed instances of mutual support of both modes of thinking, but also cases in which a strong focus on statistical thinking or critical thinking appeared to impede the other mode of thinking, respectively. The findings can inform the further development of hybrid tasks: Based on the observations, the task format can be enriched with specific reflective stimuli intended to support a fruitful interplay of statistical thinking and critical thinking.

Keywords: Hybrid tasks, critical thinking, statistical thinking, scientific reasoning, task design

\section{Introduction}

Promoting higher order thinking of learners is a goal which is relevant beyond the mathematics classroom. For example, when thinking of mathematical literacy as a competency with a focus on real-life contexts in an individual's life environment (e.g., OECD 2003, 2012), higher order thinking skills are a great support: It is especially true that when mathematical knowledge is used for analysing real-life situation contexts, this knowledge use tends to involve higher order thinking. Whereas the justification of goals for the mathematics classroom both on the level of mathematical content and on the level of higher order thinking can be considered as established, combining these goals as far as task design is concerned raises questions that need attention. This would include questions such as the following: Can tasks stimulate both content-related thinking and higher order thinking in learners and how may these modes of thinking interact when working on such tasks? In particular, it needs to be established whether the modes of thinking complement each other, support each other mutually, whether they may occur side by side without interfering, or whether 
they may even impede each other. These issues have both a theoretical and an empirical dimension, and there is a need for empirical evidence as well as for theoretical analyses addressing these questions for specific mathematical content and specific aspects of higher order thinking.

Accordingly, this study focuses on this need for research, by investigating how so-called hybrid tasks -as intended by their design-can stimulate both content-related and higher-order thinking. By hybrid tasks, we understand tasks which are designed to elicit learners' content domain-specific and domain-transcendent thinking. More specifically, the analysis is centred on the example of hybrid tasks in the content area of statistics, which aim at the same time at addressing aspects of critical thinking. We choose the example of statistical thinking (ST) and critical thinking (CT) as both of them stand for key areas of citizens' participation in society (e.g., Wild and Pfannkuch 1999; McPeck 1981). For exploring this field, theoretical considerations of interdependencies of ST and CT open up perspectives for an empirical analysis of thinking-aloud interview data which can provide insight into thinking processes stimulated by these hybrid tasks. In the first empirical step presented here, we chose adult learners in order to generate rich interview data. In addition, our interviewees were all mathematics teachers, as this group were most likely to possess the relevant content skills, and to therefore provide optimal conditions for our focus on the interactive dynamic between ST and CT, unimpeded by concerns about content competence. The fact that interaction between individual and task is significant independent of the age of the individual and the sophistication of the elicited performances suggests that insight is most likely to arise where the ST-CT dynamic is not masked by difficulties with content. The analytical results have implications for the refinement of hybrid task design, so as to foster the learners' monitoring of their own thinking: The evidence suggests that additional structuring reflection prompts might be required to support some learners (e.g., secondary students) to combine statistical and critical thinking strategies productively.

In the following, we first introduce the theoretical background and this will lead to an examination of the relative disconnectedness of approaches to ST and CT. A focus on the thinking element 'evaluating claims' provides a domain within which to analyse the interrelatedness of CT and ST and to identify the implications for hybrid task design. Further refinement of the hybrid tasks is informed by consideration of the thinking required of the individuals who work on the tasks, consistent with the theme of this special issue. Based on the research questions, the design of the study and the interpretive bottom-up analysis are described. We then report results of the study, which will be discussed in the concluding section, in which we also discuss a possibility of further task improvement based on the findings.

\section{Theoretical background}

The notion of mathematical literacy (e.g. OECD 2003) targets future citizens' competencies of full participation in society and hence on well-founded individual autonomy. When building up mathematical literacy, students acquire content-related mathematical knowledge, skills, and the readiness to make use of this knowledge and these skills for flexibly solving problems they encounter in their lives (cf. Weinert 1999, 2001; Neubrand 2001). In this regard, modelling competencies (e.g., Blum et al. 2007; Blum 2007; Kuntze 2010) play a key role for mathematical literacy. A key aspect of modelling consists in connecting mathematical knowledge and skills with situation contexts. These requirements are also described in the modelling cycle (e.g., Blum and Leiss 2005; Blomhøj and Jensen 2003), according to which modelling mediates between the domains of mathematics and of the "rest of the world" (Blum and Leiss, 2005). Amonst other benefits, being able to carry out 
translation processes between these domains helps learners to explore and describe life contexts by mathematical means, to draw conclusions from mathematical results for the situation context, and by these means to support a learner's own judgement (e.g. OECD 2012; Blum 2007; Maaß 2006; Lesh et al. 2010).

Such aspects of using mathematics for real-life contexts appear not to be far away from elements of critical thinking (cf., e.g., Lipman 1991; Mc Peck 1981; Ennis 1989): For instance, learners are required to critically review, e.g., mathematical results for their meaningfulness for specific situation contexts, to derive conclusions for situation contexts, to evaluate whether these conclusions fit the context or provide useful insight, or whether mathematical results need to be challenged by additional information about the context or additional mathematical considerations. According to Lipman (1991), CT is defined as "thinking that enables judgment, is based on criteria, corrects itself, and is context-sensitive" (p. 124) -which suggests an intersection domain which has not been described sufficiently so far for many content domains. For that reason, in the following we enter into a first theoretical analysis of connections, focusing on the example of ST and its relationship with CT.

\subsection{Statistical Thinking (ST)}

The points introduced in the previous section are especially important for contexts which require dealing with data and making use of statistics. Modelling competencies can be described specifically with respect to this content area (Kuntze et al. 2008; Kuntze 2010, 2013). As argued elsewhere (Kuntze 2010, Kuntze et al. 2008), we assert that modelling competencies can be more precisely described when considering modelling as being specific to particular content domains. Modelling related to data is very often intertwined with using and dealing with representations of data. Already when data have to be read from a diagram, in most cases mathematical models have to be used, as data are represented in diagrams with the help of mathematical models (e.g.. relative frequencies translated into angles, amounts of money represented by surface areas or even volumes). In order to interpret the diagram appropriately, or even when simply reading a value which is somehow represented in the diagram, a modelling cycle has to be carried out (Kuntze 2013; Kuntze et al. 2008, Kuntze et al. 2015; cf. Wild and Pfannkuch 1999). Take for example the question, "How much money has been spent for health in 2015?" The mathematical models that underlie a corresponding diagram have to be explored in order to read information from a diagram (e.g., How is time represented? How can information about amounts of money be extracted from the diagram?). In this process, validation steps may be necessary, in which, for instance, interpretations of data read from a diagram have to be checked against further information provided by the diagram. In this sense, mathematical modelling is almost inseparably intertwined with statistical thinking. Indeed, for statistical thinking (ST), real-life contexts correspondingly play an important role: statistical data come from situation contexts, and results of statistical modelling have to be interpreted against the background of situation contexts when drawing conclusions for the situation context in question, or when evaluating data-based statements about the situation context.

In the modelling process, two specific overarching strategies can describe key aspects of ST (cf. Shaughnessy 2007), namely, strategies of manipulating data by reduction (Kröpfl et al. 2000), and strategies of dealing with statistical variation (Watson and Callingham 2003; Watson 1997). Manipulating data by reduction (Kröpfl et al. 2000) means that when being confronted with and when processing data, overviews have to be generated by reducing the amount of information, e.g., 
when calculating the mean value or the standard deviation. At the same time, thinkers have to be aware that by doing this, information is usually lost, and that statistical indicators or representations of data might not reflect all important aspects of the original data set. Mostly, ST elements that can be described according to these strategies correspond to modelling steps and also to steps involved in critically examining models.

Strategies of dealing with variation (Watson and Callingham 2003; Watson 1997; Wild and Pfannkuch 1999) respond to the phenomenon that data in most cases contain random deviations or potential errors, together with variation which might be meaningful for a particular context. Models have thus to take into account that not all variation in data are meaningful. In the words of Konold and Pollatsek (2002), ST in this sense has to identify the "signal" in the "noise".

\subsection{Critical thinking (CT)}

Somewhat beyond these considerations, Wild and Pfannkuch (1999) mention critical thinking (CT) among the constituents of their model of statistical literacy. Gal (2004) includes a critical stance as dispositional element among the necessary factors for statistical literacy. However, these approaches are not very explicit about the theoretical reference framework of CT and about how $\mathrm{CT}$ interferes in ST, whether or what elements of CT are an integral part of ST, or rather should be considered as context variables or covariates of ST. Literature focusing on ST has so far not established satisfactory connections with $\mathrm{CT}$ research frameworks. Nevertheless, aspects of CT appear as relevant, in particular when dealing with situation contexts that require ST.

CT can be considered as higher order thinking which relies on the self-regulation of thinking processes, on the construction of meaning, and on the detection of patterns in rather disorganized structures (Ennis 1989). CT is complex and often identifies multiple solutions that have advantages and disadvantages, rather than a single clear solution. CT uses heterogeneous criteria and is adaptive to contexts marked by uncertainty. This description of the notion of CT already suggests links with ST, such as dealing with uncertainty, contradictions and the critical evaluation of given claims (cf. McPeck 1981; cf. Kuntze et al. 2013). Dealing critically with such information-a crucial aspect for both CT and ST-demands critical/evaluative thinking based on rational thinking processes and reflective decision-making (cf. Aizikovitsh and Amit, 2008; Aizikovitsh-Udi 2012).

There is a relatively wide-spread range of definitions for CT (Dewey 1933; Innabi and Sheikh 2007; Lipman 1991; Siegel 1988). For example, McPeck (1981) defined CT as the "skills and dispositions" necessary to "appropriately use reflective scepticism" (p. 24), whereas Lipman (1991) characterises $\mathrm{CT}$ as "thinking that enables judgment, is based on criteria, corrects itself, and is context-sensitive" (p. 124). Willingham (2007) describes CT as "seeing both sides of an issue, being open to new evidence that disconfirms your ideas, reasoning dispassionately, demanding that claims be backed by evidence, deducing and inferring conclusions from available facts, solving problems, and so forth" ( $p$. 8) -a definition which enumerates specific aspects of CT. Also Ennis's (1987) approach, characterizing CT as "reasonable, reflective thinking that is focused on deciding what to believe and do" (p. 10) is specified by a taxonomy of sub-aspects.

This focus is particularly fruitful, as Ennis explicitly describes aspects of CT as influencing how the person who employs it interacts with the outside world. This is a perspective that is also employed when considering the relevance of ST for real-life situations. In Ennis' approach, two domains of CT are distinguished, namely so-called "abilities" and "dispositions". "Abilities" refer to the cognitive aspects of $\mathrm{CT}$, to knowing how to think critically and what critical questions to pose (Ennis' list of 
abilities includes identifying the focus, defining terms, identifying unstated assumptions, judging source credibility, etc.). "Dispositions" refer to a "critical spirit"-a notion of when or whether something ought to be engaged with critically. Moreover, dispositions include caring that beliefs be true and that decisions be justified, taking care to present a position accurately and clearly (Ennis 2002, 1989).

An associated research instrument for $\mathrm{CT}$ is the so-called Cornell Critical Thinking Test Level Z, which was developed by Ennis and his colleagues (Ennis and Millman 2005). The test includes general content with which students tend to be familiar. It includes five sub-tests and evaluates different aspects of $\mathrm{CT}$ including induction, deduction, value judging, observation, credibility, assumptions and meaning (which includes definition, sensitivity to meaning, and ability to handle ambiguity). The process of $\mathrm{CT}$, however, involves an overlap of these aspects as they are all dependent on each other. Ennis and Millman (2005) state that this test is a general ability test, involving many aspects of CT. Consequently, not only on the theoretical level, different CT aspects may differ in importance for ST, so that the empirical examination of the interrelatedness of ST and CT needs a careful approach. For this reason, research about interdependencies between $\mathrm{CT}$ and ST should be intentionally sensitive to sub-components of CT (and ST), and a solid common theory base is needed. Before presenting such a framework theory in section 2.4, empirical findings about interdependencies of CT and ST (in the following section) should be taken into account.

\subsection{Empirical findings relating Critical Thinking to Statistical Thinking}

There are prior studies in which relationships between CT and ST have been investigated in a quantitative correlational design. For instance, Royalty (1995) found a significant $(p<0.01)$ correlation of $r=.49$ between the scores on the Cornell CT Test (Ennis and Millman 2005) and on a selection of statistics items. However, Royalty (1995) hardly describes the structure or the model associated with the ST instrument used in the study, nor is the correlation found in the study discussed from a content point of view. Moreover, the instrument by Ennis and Millman (2005) uses statistical contexts for the CT measurement in some items, which further restricts potential implications from Royalty's study. Royalty's study focuses on the question of generalizability of CT, and ST is considered as a domain-specific variable. This research thus calls for in-depth analyses about how CT and ST may be interdependent, which is clearly relevant for (hybrid) task design with a simultaneous focus on both ST and CT.

Moreover, there are empirical findings indicating that $\mathrm{CT}$ can be fostered by teaching that is focused on ST and probability: Aizikovitsh-Udi (2012) found that scores on the Cornell CT test (Ennis and Millman 2005) improved after a teaching intervention. These findings suggest that the growth in CT might have been connected to the development of competencies in the area of ST and probability. We thus conclude that empirical findings suggest interdependencies between CT and ST. However, there is hardly any generalizable empirical evidence as to how these forms of thinking are interconnected, how components of CT and ST may interact, and whether/how they can be developed simultaneously by specific task formats. For task design, there is hence a need of analysing how ST and CT are interdependent.

\subsection{Evaluating claims-a key thinking element in the intersection domain of CT and ST}


For describing a key intersection domain between ST and CT from a consistent theoretical point of view, a third research tradition can provide a very helpful base (cf. Kuntze et al. 2013): The theory related to scientific reasoning and findings related to limitations in scientific reasoning (Kuhn 1989; Bullock and Ziegler 1994; Klahr and Dunbar 1989; Tschirigi 1980; Thomas 1997; Reiss and Thomas, 2000; Kuntze 2004) can help to describe thinking related to the evaluation of claims-also with respect of ST and CT. The core of this theory is that in scientific reasoning, theory and hypotheses have to be looked at as separate from (empirical) evidence (Kuhn et al. 1988). Successful scientific reasoning consists in correctly evaluating theory and hypotheses against the evidence. Strategies related to scientific reasoning are thus

- generating hypotheses, comparing with evidence;

- considering theory as potential subject to revision;

- using strategies of falsification of hypotheses; and

- discarding theory, if the evidence contradicts the theory.

In this perspective, strategies of evaluating claims based on the scientific reasoning approach may take the form of the following 'local' strategies in CT and ST respectively, which can then be compared for identifying, e.g., commonalities between CT and ST. Here are three examples:

- Keep theory (i.e. claims) distinct from evidence: In line with many conceptualisations of CT, this may be described by showing a critical stance and keeping a certain distance from claims that thinkers may encounter.

In ST, separating evidence from theory would imply for example that a clear distinction is made between data and interpretation of data.

- Generate hypotheses/claims: The general strategy of generating hypotheses or claims is reflected in CT in activities of drawing one's own conclusions from an examination of a particular situation context, for instance.

In ST, generating interpretations based on data-related modelling would be a relevant thinking element.

- Challenge claims actively: In CT, strategies of questioning assumptions can be seen as a local set of CT strategies connected with this point. For instance, asking where a claim or an assumption comes from or on what base it has been made are connected with such CT strategies.

In ST, corresponding local strategies may consist in checking models and underlying assumptions which lead to interpretations of data, questioning the data's origin, questioning data gathering methods and procedures including questions of sampling, as well as exploring variation for possible counter-evidence which might afford rejecting data-related claims.

This overview shows that there is an intersection domain of ST and CT which can be described by the focus on evaluating claims as outlined above. However, the sub-aspects presented above suggest that CT and ST may stand for a specific emphasis within the sub-aspects. Qualitative empirical analyses (Aizikovitsh-Udi and Kuntze 2014) suggest that it makes sense to consider the domains of "CT within ST" and "CT enriching ST", depending on how necessary CT components are for successful ST. 


\subsection{Hybrid task design}

For stimulating both ST and CT by the same task, so-called hybrid tasks (e.g., Aizikovitsh-Udi et al. 2013) have a high potential. For instance, when asked to evaluate statistics-related claims, learners can be encouraged to use CT strategies as well as ST strategies for carrying out the modelling steps that are needed for finding answers to the task. Even though modelling requirements are not considered to be a necessary element for hybrid tasks in the general sense, they play a role for hybrid tasks connecting ST and CT, given the interrelatedness of ST and modelling as described in section 2.1. For highlighting characteristics of these tasks more specifically, a first sample task is shown in Figure 1. This task is designed for secondary students up to young adults. The task can be considered as standing for requirements citizens have to meet when being confronted with data represented in diagrams-as they can be found throughout the media, for example.

In the task, a diagram presents data about the numbers of deaths and births in Germany from 1945 on. The claim "the Germans don't have enough children", introduced as a newspaper's headline, can be interpreted against statistical consideration of these data. For answering the question "from which year on has the population been decreasing?" carrying out modelling steps beyond just reading data from the diagram is necessary: As births and deaths can be considered as "incomings" and "outgoings" of a "pool" which may represent the population, a corresponding reservoir-like model affords identification of the intersection point(s) of the two graphs as meaningful for answering the question. However, as immigration or emigration may have a further impact, it would be very welcome if thinkers asked for more data in order to be able to fully answer, or if they restricted their answer to the simplified situation of only considering the given data (Kuntze et al. 2008). Asking for more data would correspond to a correct solution step in which also aspects of CT would play a role: From the CT point of view, this may be seen as a strength of this task, as the completeness of the given data may be questioned in this regard.

"The Germans don't have enough children", was a recent newspaper's headline. Consider the following diagram about the development of the German population:

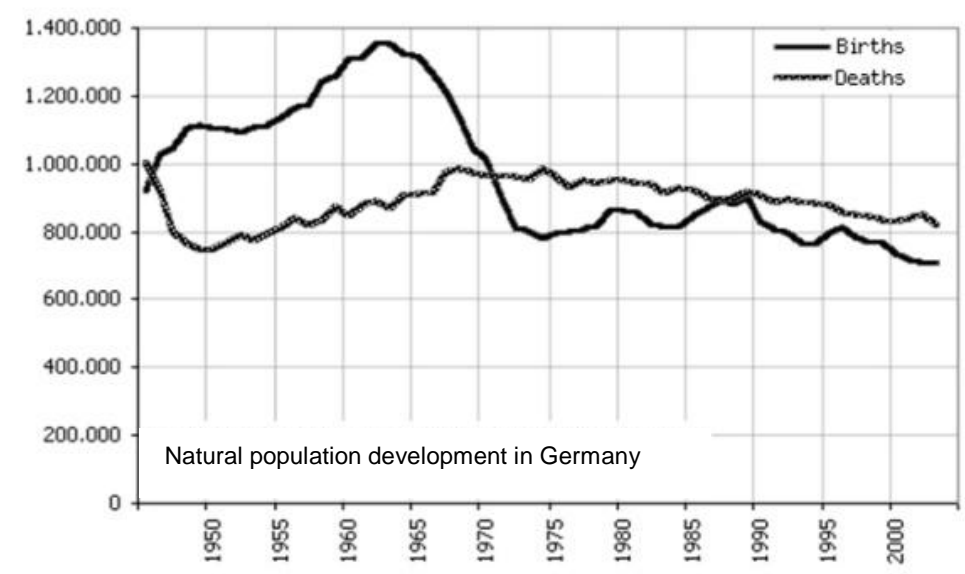

From which year on has the population been decreasing? Justify your answer.

Figure 1: Task “population” (Kuntze et al. 2008) 
Another example of a hybrid task is shown in Figure 2. In this task, two data-based claims are suggested, and the learner is asked to link these claims to the given data by corresponding argumentation that disproves the claims. Evaluating data-related claims is thus at the centre of this task. Dealing with variation plays a visible role in modelling and for successfully addressing this task, but also CT strategies of questioning the data source or assumptions related to the headache context may enrich the learners' experience with this task: Is, for instance, the speed of recovery the only quality criterion of a medicine? How representative is the sample? Are there meaningful background variables which lead to the distribution of tablet 2 ? etc.

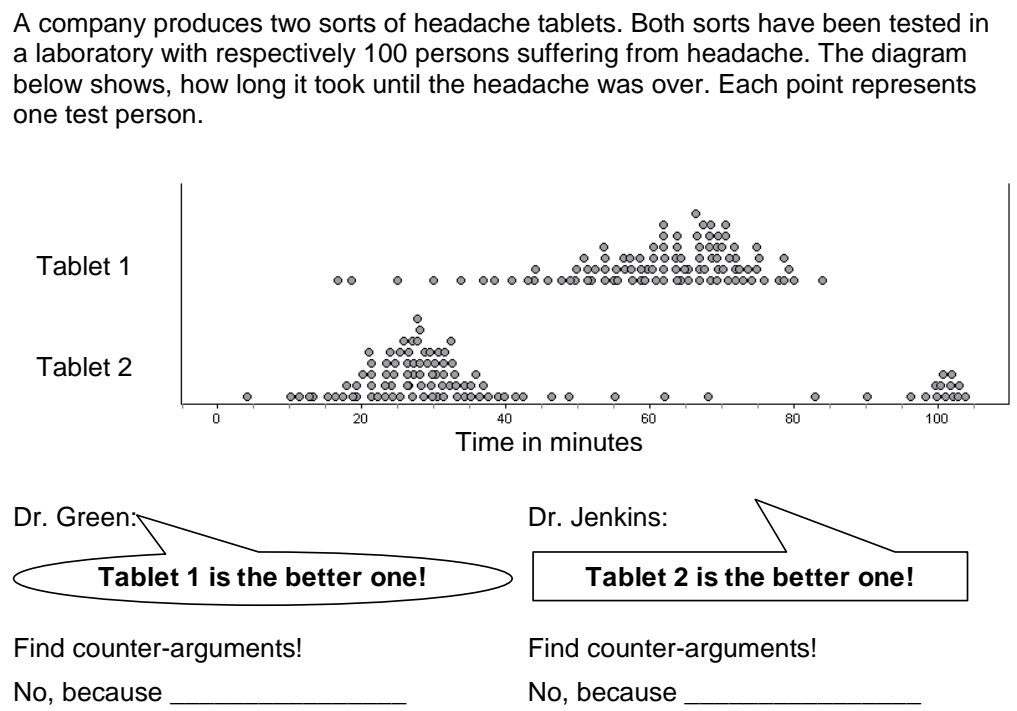

Figure 2: Task "tablets" (Kuntze et al. 2008)

These task-specific considerations shed a light on the need to find out more about the thinking of persons who are working on such hybrid tasks. For this purpose, a focus on the learners' perspective and on individual learners' thinking processes appears as crucial (Ainley and Margolinas 2015), as intended goals, and learners' activities and evoked understanding, as well as thinking processes, may differ significantly. Moreover, the hybrid tasks' subsequent refinement and ongoing design process can respond to needs that may become salient from an analysis of the learners' thinking. This paper will thus concentrate on learners' thinking as a corresponding research interest.

\section{Research Interest}

On the base of the thoughts presented above, the perspective of persons who work with the task should be a key constituent of hybrid task design, in particular as far as the interplay between the persons' ST and CT-both being addressed by these hybrid tasks-is concerned. The research interest targets also the finding out about possibilities of improving the tasks. In this sense, empirical analyses are an integral part of the ongoing hybrid task design process.

Consequently, the following research questions will guide the analyses:

- Do the hybrid tasks designed for addressing ST and CT stimulate corresponding thinking of the interviewees asked to solve these tasks? 
- How can the interdependencies between these thinking elements be described on the basis of the evidence and what does the analysis reveal about the potential benefits of combining ST and CT thinking strategies?

- On the basis of the empirical findings, is it possible to derive conclusions for improving the hybrid tasks, and if so, in which ways can the hybrid tasks be improved?

\section{Design and methods}

This research interest is mainly exploratory, and it is crucial for the empirical study that persons who work on the hybrid tasks show and verbalize their thinking. Moreover, it is helpful for this research focus if it can be expected that the interviewees will not have difficulties with partial knowledge about the situation contexts or be handicapped by a lack of possible mathematical models. Given these considerations, it was advantageous to first study the behaviours of adult learners. While this decision might restrict the generalizability of the results with respect to all target learner groups, the interviewees' level of experience was felt to be more likely to reveal how ST and CT can interact in principle, without the distorting influence of difficulties in mathematical or context knowledge, as might be the case with children. If we had focused on children with knowledge deficits rather than adults, disconnected or partially absent CT and/or ST might have proved difficult to interpret: It would have been unclear whether any such potential disconnectedness might have been a consequence of the task or a consequence of a knowledge deficit in the individual. From quantitative studies (e.g. Kuntze et al. 2008, 2015), we know that the tasks are accessible for secondary students. For example, the task in Figure 1 showed a rate of correct solutions amounting to more than $38 \%$ ( $N=549$; Kuntze et al. 2015). However our focus on higher order thinking suggested that an initial study of adult learners would provide an optimal entry point into the investigation of ST/CT interaction and the use of hybrid tasks.

Moreover, it is easier to unpack and make accessible the thinking of adult learners in thinking-aloud interviews. In order to address the research questions, we used data from think-aloud interviews with teachers from the U.S. and Israel who were asked to solve a set of such hybrid tasks. The following discussion focuses only on the population task shown in Figure 1. The interviews were transcribed and can provide insight into the interviewees' thinking processes.

The analysis was carried out in three steps: The first two steps were criteria-oriented interpretive bottom-up analyses focusing on criteria related to ST only and CT only; the third step was an analysis under a combined ST and CT perspective. We followed an interpretive approach (Mayring 2015; cf. Schreier 2012), which aimed at reconstructing individuals' thinking processes from the interview data against a background of explanation criteria drawn from the corresponding theoretical framework(s) (ST, CT, and both ST and CT with particular focus on evaluating claims according to scientific reasoning, cf. Kuntze et al. 2013). In previous analyses (e.g., Aizikovitsh-Udi et al. 2012), we observed that the combined ST and CT analysis offered the deepest understanding of the interviewees' thinking and provided at the same time insight into interactions between ST and CT, justifying the methodological approach employed. At this stage in the research process, the analyses focus primarily on the interviewees' individual thinking. Identifying more generic patterns, survey-style research designs or generalizing from a wider range of cases may be undertaken at a later stage of this research. The evidence presented and discussed here is intended to provide "proofs of existence" of specific thinking modes or patterns used by the interviewees. 
The analysis was done by two raters (the first two authors). In the criteria-oriented interpretive content analysis process, consensus could always be reached. We present and discuss examples of the interviewees' answers related to the population task shown in Figure 1. We report the original data and key results of the three analytical steps and we present answers to the research questions, which are then discussed in section 6 .

\section{Results}

We concentrate on evidence from three interviews around the task presented in Figure 1. Alex, Nena and Dana are experienced secondary mathematics teachers, Alex and Dana are from Israel, Nena from the U.S. Alex responded to this task in the following way (thinking aloud method):

Alex: The population decreases when the birth rate is lower than the death rate. According to this chart, this condition takes place from 1971 on and remains so for the duration of time covered by the chart. Actually the "area" between the two curves, over a given period, represents the accumulated decrease of the population within that period. This trend is apparently due to the dramatic fall of the birth rate in Germany that took place around the years 1963-1973, perhaps because the post-war generation had just matured? It should also be noted that before 1946 or so the population was also decreasing, probably within the World War II period.

We will first turn to the results of the analysis focusing on ST: Alex gives a complete answer concentrating on a first model based on the comparison between birth and death rates and referring to the data in a relatively precise way. He does not describe the whole model, which might resemble the reservoir-like model discussed above. Against such a mental model, the comparison between birth rate and deaths rate makes sense. Then he uses a second mathematical model, focusing on the notion of accumulated effects ("accumulated decrease"). He probably considers the time from 1971 on, as for this time period it is correct to identify the cumulative effect with a net decrease in the population. Apparently, he does not draw a direct conclusion from this second model and appears to be satisfied with the model itself. He then interprets his reading of the data by connecting it with personal knowledge about the context, speculating about sociological reasons ("post war generation had just matured"), but also referring to the data given in the diagram. Going beyond the data given in the diagram, he makes further connection to historical developments "within the World War II period". From the ST point of view, we observe the correct use of even two models, with at least one model on a relatively high level of complexity. We further see that he tries to connect the data to his context knowledge, which corresponds to a validation step in the modelling cycle.

The analysis from the CT perspective suggests that Alex first expresses a rule-like assumption, connecting population decrease with the births and deaths rates. However, the assumptions behind this rule are not identified: For instance, emigration or immigration might play a role as well. The consideration of the meaning of the area between the curves in the sense of a cumulative effect can be interpreted as giving an explanation or reason for the rule expressed in the first sentence; however this consideration does not lead to Alex questioning this rule, and no conclusion is drawn. In the third sentence we find evidence that Alex made a link between his prior knowledge about the context. He connects the data from the diagram ("years 1963-1973") to a possible explanation of the drop in the birth rate. At the same time however, he questioned his explanation, which may be seen as indicating a key CT skill. In the last sentence about the pre-1946-period, Alex focuses on the 
specific question, by adding that in this period, the population was also decreasing according to the diagram, and again he connects with additional knowledge ("World War II period").

If we combine the ST and CT perspectives, Alex's answer suggests a strong initial focus on mathematical models that he used for the statistical context and that enable him to give an answer immediately. He even complements the first model by a second deepened model. Including the CT criteria, this strong ST lens in his answer might have somewhat distracted Alex from the critical consideration of assumptions: we do not observe either the identification or a review of the assumptions that underlie his mathematical models. In contrast, by connecting to his situationspecific knowledge and hence to a certain extent validating the results from his mathematical model(s), he shows a mastery of relevant ST skills. As he also considers the intersection point at the very left of the two curves and even appears to go beyond the data given in the diagram, he thinks in a certain detail-oriented way, focusing specifically on the section of the diagram showing that the death rate is higher than the birth rate before 1946. Alex hence connects data and their interpretation by his model, and deduces a very complete and detailed consideration of possible statements that might be derived from the data presented in the diagram. This shows how CT within ST (cf. Kuntze et al. 2013) can enhance ST related to the given data.

With respect to the first research question, there is clear evidence that both ST and CT have been stimulated-even if Alex concentrated on CT within ST and could additionally have focused on further CT aspects. Our second research question concerned interdependencies between ST and CT. In the case of Alex' answer, ST appears to be dominant and it profited from CT steps. Further use of CT might have been impeded by the dominant ST. A potential improvement of the task (see third research question) could consist in making problem solvers more aware of further possible CT strategies, which Alex did not use in his answer.

Dana's answer gives us insight into her thinking process when working on the task:

Dana: The graph shows a relatively steady state of deaths through the year 1950 and on. The births on the other hand have a big boom during 1955 till the 1970ies. It doesn't have the information on how much population there is in general. If we start to look at the graph from the first years of its information-1950-we can see that in those years-1950 through 1970-the number of births was much higher than the number of deaths, meaning that the population would be increasing. In the years 1970 and on, the number of deaths is higher than the number of births, and so the population would be decreasing. There is a small point between 1985 and 1990 in which the numbers of deaths and births are equal, but it changes again and continues to be more deaths than births. It seems that after 1990, there is a decrease in both births and deaths. However, it still is more deaths than births, this means that the population is decreasing. To sum it up, the paper is referring to all the years after 1970, with the small exclusion of the point between 1985 and 1990 in which there is the same number of deaths and births.

We first consider the analysis based on ST criteria: In her answer Dana starts with an exploration of the given diagram. She comprehends the data represented in the diagram and identifies time periods with certain properties as far as birth and death rates are concerned. She appears to deal successfully with variation; for example, when concluding that there is a "relatively steady state of deaths through the year 1950 and on". At the end of her third sentence, she turns to deducing a claim about the population development, which is grounded in her prior description of the data 
("meaning that the population would be increasing"). We can hence conclude that she has constructed a corresponding mental model for the population. On this basis, she now approaches the question given in the problem and describes the periods when the population has been decreasing. The answer is very complete in the sense that she carefully considers the year in which the two rates appear to be equal between 1985 and 1990 . The claims she makes are followed by references to the birth and death rates, so she constantly comes back to her initial argumentation based on the graph.

From the CT perspective, Dana first reviews which information is given in the diagram: In the very beginning she states that no information about the total population is given ("it doesn't have the information how much population there is in general"). In the CT perspective, this is a strong sign of being aware that there might be more details beyond the given information which could be relevant for evaluating the newspaper's headline or for answering the question. However, she does not specifically question the given data regarding potential effects of immigration or emigration. She then appears to discover that she is able to answer the given question only on the base of the rates of deaths and births by considering what their comparison may mean for the whole population ("meaning that the population would be increasing"). She then formulates an answer to the question and this apparently has the status of a first hypothesis for her: She even appears to check this hypothesis by generating counter-evidence when going through the data given in the diagram. For instance, she mentions that the birth (and death) rates went down after 1990 ("it seems that after 1990 there is a decrease in both births and in deaths"). She concludes with the assumption that the newspaper "is referring to all the years after 1970[...]". This conclusion lacks justification, as the problem does not give evidence about the relationship between the headline and the diagram. However, this conclusion stems from her subjective insights, as she has very carefully checked all the periods shown in the diagram. A verification against the given (and/or even the non-given) information would however have been possible and would have corresponded to a higher degree of $\mathrm{CT}$ at this point.

We now present results from the combined CT and ST perspective: Dana's answer shows both ST and CT thinking skills. Her thinking process appears to start with a relatively careful review what information is given and even what potentially relevant non-given information could have been useful. Dana reads not only data from the diagram, she already employs first cross-comparisons in a qualitative interpretation of the graphs and deduces first interpretations from elementary modelling steps ("a big boom during 1955 till the 1970's"). This description of the given data very probably helps her to connect it to the context and to identify other variables of the population context which are not given ("it doesn't have information on how much population there is in general"). This consideration of a question beyond the given information is relevant in terms of $\mathrm{CT}$, but at the same time Dana's (ST-related) modelling steps in her first review of the data in the diagram can be considered as a facilitating element that encouraged her to make the statement about the non-given information. In the following thoughts, Dana keeps coming back to the data in the diagram as she checks her interpretations; that is, her hypotheses against the data. She hence separates the evidence from her hypothesis, and deals critically with it: as described above, the interpretation suggests that we have evidence of her readiness to reject the interpretation of the data if the data in the diagram had yielded counter-evidence.

As far as the first research question is concerned, Dana's interview also shows that both CT and ST have been stimulated by the population task. In Dana's case, the reasoning focus is closer to the examination of data and their interpretation, even beyond the claims given in the task. This is relevant also in the second research question: We can see how CT strategies help to monitor ST 
when reading from the diagram and interpreting data, and hence how they help to support datarelated modelling.

Nena's thinking related to the same task was less successful:

Interviewer: What do you think? From which year on has the population been decreasing?

Nena: Well.....the population has been decreasing since 1963 until about 1973, where the population begins to rise a bit..... but it is still down since $1963 . . .$.

Interviewer: Are you confident about it?

Nena: of course... I am sure! You can look at this problem mathematically, anywhere there is a positive slope you could say the population is increasing, where there is a negative slope the population is decreasing. But compared to 1963, it's always been down. Am I right?

Interviewer: Sorry, I can't say.

Interpreting the evidence from the perspective of $S T$, Nena chooses an inappropriate statistical model for making sense of the data given in the diagram. She appears to focus on the birth data only, and she draws her conclusions from a mathematical consideration of slopes. Even when encouraged by the interviewer, she does not check this model against the background of the full data given in the diagram.

Seen from the perspective of $C T$, Nena expresses an initial assumption, interpreting the graph of births as completely determining the population development. Even when asked to reflect on this assumption, Nena does not generate possible counter-arguments for testing her initial assumption, nor does she appear to question this assumption. Consequently, her way of dealing with assumptions appears to rather unsuccessful; she tends to seek for confirming evidence rather than for evidence that might challenge her initial assumption.

Looking at the relationships between CT and ST in more depth, we again turn to the combined analysis: At the very beginning of Nena's thinking process, she shows a partial or incomplete perception of the evidence, focusing on the birth data from 1963 on. This selective focus may have been a result of the headline given in the diagram ('The Germans don't have enough children'), which can be interpreted as an assumption in CT terms. This headline may hold from about 1972 on, or, within Nena's misinterpretation of the births determining the population, from the turning point in 1963 on. Nena does not question the given headline, which would have been a characteristic of CT. This stance of questioning assumptions derived from data is also an important aspect of ST performance. In the next statements by Nena, it becomes even more apparent just how important questioning assumptions can be for ST: Nena does not question her first-and partial-interpretation of the diagram and hence does not challenge her model of the data in terms of ST, neither by looking at the complete curve of the births, nor by developing a model of considering the population as a sort of 'reservoir' with 'incomings' and 'outgoings' as it was seen by Alex (above).

In this context, it is interesting that Nena emphasises that it is possible to "look at this problem mathematically", which suggests that she sees a discrepancy between considering the situation from the perspective of a mathematical model on the one side and looking at it from the perspective of the context (population and children born in Germany) on the other side. Possibly Nena sees the mathematical or statistical model as an authority that justifies the appropriateness of the assumption 
instead of questioning the model chosen initially. We may conclude from this combined analysis that the shortcomings in CT go hand in hand with shortcomings in ST and that the elements of reasoning in both domains interfere and interact. More CT might have helped Nena also in her ST. For task development according to the third research question, additional CT prompting might be helpful for anyone attempting the task. As far as the second research question is concerned, Nena's data suggest how knowledge and awareness of both CT and ST can be mutually beneficial, reinforcing related reasoning approaches.

Summing up, the results around the population task given above suggest that both ST and CT were stimulated by this task. In many cases, ST and CT mutually supported each other or even might be considered as the same thinking activity. In other cases, in the interviews, it appears that ST might become dominant and somewhat hinder CT. For further refinement of the task design, specific guidance for using CT strategies might be beneficial for the learners' ST and CT.

\section{Discussion and conclusions}

Overall, we may conclude from the data that the hybrid tasks' simultaneous focus on both ST and CT is a goal that the tasks could reach: In the thinking-aloud interviews, we have strong evidence that both ST and CT were continuously stimulated and that both can interact productively. In some cases, the ST- and CT-oriented analyses revealed that the same thinking process was relevant for both modes of thinking; in other instances specific thinking elements with an emphasis either on ST or on CT were observed. In most cases displayed here, ST and CT elements mutually supported each other or deficits were visible in both domains at the same time. But there were also cases in which one of the domains, or even an element in one of the domains was dominant and might have hindered the full development of thinking in the other domain(s). For this second case, additional findings reported by Aizikovitsh-Udi and colleagues (2012), and Aizikovitsh-Udi and Kuntze (2014), can provide further insight into what path thinking can take in such cases. Cases of dominance of one mode of thinking, which may even become an obstacle for the other mode of thinking, can therefore occur when working on hybrid tasks.

This raises the question as to whether and how the hybrid tasks presented previously can be improved, so that the combination of both modes of thinking in the process of working on hybrid tasks can be supported to complement each other productively. The results reported above suggest that unquestioned assumptions or claims could act to restrict the quality of thinking processes as reflected in the interview answers. For improving hybrid task design in the area of ST and CT, it therefore makes sense to strengthen the focus on supporting scientific reasoning (Kuhn 1989; Bullock and Ziegler 1994; Klahr and Dunbahr 1989; cf. Kuntze et al. 2013) related to ST and CT. Such a scaffolding approach is even more likely to be beneficial when the tasks are undertaken by secondary students. We would thus like to recall aspects such as keeping claims, hypotheses, theory, and assumptions distinct from evidence, comparing claims with evidence, considering claims as potential subject to revision, explicitly using strategies of falsification of claims and discarding them if evidence contradicts the claim. We suggest using these aspects as guiding thoughts for the development of hybrid tasks. In the following, we would like to show in which form corresponding specific support for the learners could be offered in hybrid tasks.

Figure 3 shows an example of a reflection-oriented instructional framing of one of the tasks presented above, namely the population task. 


\section{Hybrid task version with CT prompting (aspect: dealing with hypotheses)}

When looking at data in diagrams or tables, one should always distinguish the data on the one hand from interpretation or claims which someone may make when looking (or even not looking) at the data. The data are the "facts", the interpretation and claims are sometimes opinions that can be inconsistent with the data.

In the following task, there are data as well as interpretation of data. Figuring out what are data and what is interpretation may help you when solving the task.

"The Germans don't have enough children", was a recent newspaper's headline. Consider the following diagram about the development of the German population:

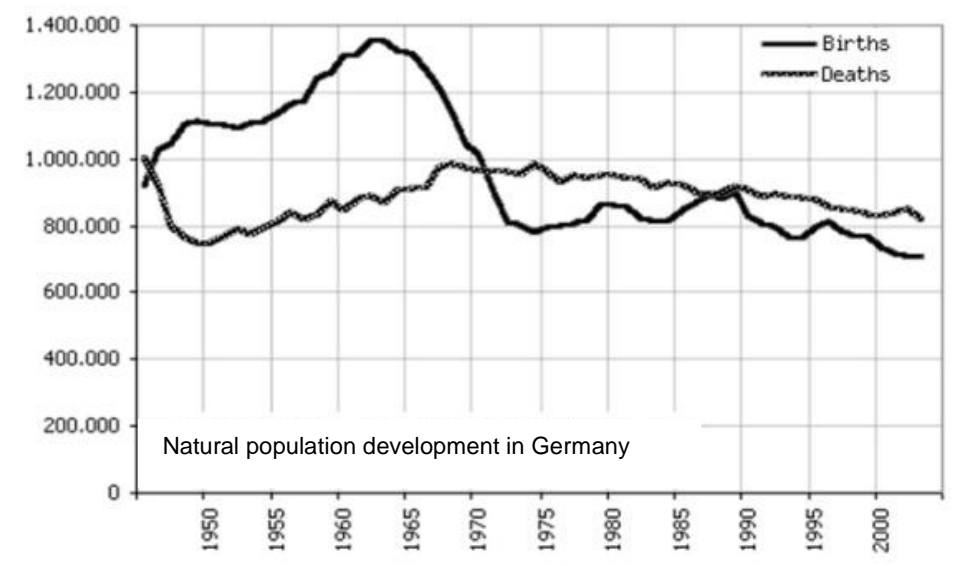

From which year on has the population been decreasing? Justify your answer.

Take a look at the task: Where can you see data, where can you see interpretation? [Suggestion: mark data in green, interpretation/claims in red]

Answer the task.

Having solved the task, how have you tried to distinguish between what are data and what is interpretation of data?

What is your interpretation of the data, and how do the data support this interpretation?

Figure 3: Task framed by CT prompting related to dealing with hypotheses

The aim of this specific instructional framing is to support a productive interaction of ST and CT. The first part of the framing can be seen as an introduction to the task which aims at drawing the learners' attention to the epistemological status of claims and evidence especially in the form of data. The framing hence opens up a meta-level consideration of the task and its content, focused on a content-adapted form of scientific reasoning. Moreover, the work on the task itself is complemented by questions which target the learners' reflective activity around the previously introduced aspects of scientific reasoning. For instance, the question "In solving the task, how have 
you tried to distinguish between what is data and what is interpretation of data?" is intended to stimulate the learners' reflection on their thinking activities. Beyond the possible case that the learners might not have been aware of relevant thinking elements, the question is also thought to be an additional opportunity to come back to the task itself and to add and deepen solution steps. The framed and enriched task in Figure 3 should be understood as the first task in a series of tasks, in which reflection related to evaluating claims and assumptions should continuously accompany the work on the tasks.

A follow-up research interest would be to analyse thinking processes of younger learners (e.g., secondary school students) when working on these framed hybrid tasks. This is important because empirically examining the targeted learners' work with tasks should be an integral part of task design (cf. Ainley and Margolinas, 2015; pp. XXX, in this special issue). Further follow-up questions concern the role of hybrid tasks in other content domains and also other forms of their further development in this content area. For instance, if learners are asked to actively work with data (e.g., with the help of digital tools), the development of claims or the critical monitoring and evaluation of activities in data analysis might play an intensified role with a potential shift towards the working process. In this sense, this study is a first step which aims at informing further necessary research steps.

\section{References}

Ainley, J., \& Margolinas, C. (2015). Accounting for student perspectives in task design. In A. Watson \& M. Ohtani (Eds.), Task design in mathematics education (pp. 115-142). New York: Springer.

Aizikovitsh-Udi, E. (2012). Developing critical thinking through probability models, intuitive judgments and decision-making under uncertainty. [Doctoral dissertation]. Saarbrucken, Germany: Lambert Academic Publishing.

Aizikovitsh-Udi, E., \& Amit, M. (2008). Developing critical thinking in probability lesson. In O. Figueras, J. L. Cortina, S. Alatorre, T. Rojano, \& A. Sepúlveda (Eds.), Proceedings of the $32^{\text {nd }}$ Conf. of the IGPME (Vol.2, pp. 9-13). Morelia, México: Universidad Michoacana de San Nicolás de Hidalgo.

Aizikovitsh-Udi, E., Clarke, D. J., \& Kuntze, S. (2013). Hybrid tasks: Promoting statistical thinking and critical thinking through the same mathematical activities. In A. Watson, et al. (Eds). Proceedings of ICMI Study 22 Task Design in Math. Educ., (pp. 457-467). Oxford: ICMI.

Aizikovitsh-Udi, E. \& Kuntze, S. (2014). Critical thinking as an impact factor on statistical literacy. In K. Makar, B. de Sousa, \& R. Gould (Eds.), Proceedings of ICOTS9. Voorburg: ISI.

Blomhøj, M. \& Jensen, T.H. (2003). Developing mathematical modelling competence: Conceptual clarification and educational planning. Teaching Mathematics and its Applications, 22(3), 123-139.

Blum, W. \& Leiss, D. (2005). Modellieren im Unterricht mit der „Tanken“-Aufgabe. mathematik lehren, 128, 18-21.

Blum, W., Galbraith, P., Niss, M., \& Henn, H.-W. (Eds.). (2007). Modelling and applications in mathematics education, New ICMI Studies Series no. 10. New York: Springer.

Bullock, M. \& Ziegler, A. (1994). Scientific thinking. In F. Weinert \& W. Schneider (Eds.), The Munich Longitudinal Study on the Genesis of Ind. Competencies. Munich: MPI.

Dewey, J. (1933). How we think: A restatement of the relation of reflective thinking to the educative process. Boston: Heath. 
Ennis, R. H. (1987). A taxonomy of critical thinking dispositions and abilities. In J. B. Baron \& R. J. Sternberg (Eds.), Teaching thinking skills: Theory and practice (pp. 9-26). New York: Freeman.

Ennis, R. R. (1989). Critical thinking and subject specificity: Clarification and needed research. Educational Researcher, 18, 4-10.

Ennis, R. H. (2002). Goals for a critical thinking curriculum and its assessment. In A. L. Costa (Ed.), Developing minds (3rd ed., pp. 44-46). Alexandria, VA: Association for Supervision and Curriculum Development.

Ennis, R. H., \& Millman, J. (2005). Cornell critical thinking test, level Z (5th ed.). Seaside, CA: The Critical Thinking Company.

Gal, I. (2004). Statistical literacy, meanings, components, responsibilities. In D. Ben-Zvi, \& J. Garfield (Eds.), The challenge of developing statistical literacy, reasoning and thinking (pp. 47-78). Dordrecht: Kluwer.

Innabi, H., \& Sheikh, O. (2007). The change in mathematics teachers' perceptions of critical thinking after 15 years of educational reform in Jordan. Educational Studies in Mathematics, 64(1), 45-68.

Klahr, D. \& Dunbar, K. (1989). Developmental differences in scientific discovery processes. In Klahr, D. \& Kotovsky, K. (Eds.), Complex information processing (pp. 109-143). Hillsdale, New Jersey: Erlbaum.

Konold, C. \& Pollatsek, A. (2002). Data analysis as the search for signals in noisy processes. Journal for Research in Mathematics Education, 33(4), 259-289.

Kröpfl, B., Peschek, W. \& Schneider, E. (2000). Stochastik in der Schule: Globale Ideen, lokale Bedeutungen, zentrale Tätigkeiten. mathematica didactica, 23, 25 - 57.

Kuhn, D. (1989). Children and adults as intuitive scientists. Psychological Review, 96. 674 689.

Kuhn, D., Amsel, E. \& O'Loughlin, M. (1988). The development of scientific thinking skills. San Diego, California: Academic Press.

Kuntze, S. (2004). Wissenschaftliches Denken von Schülerinnen und Schülern bei der Beurteilung gegebener Beweisbeispiele aus der Geometrie. Journal für MathematikDidaktik, 25(3/4), 245-268.

Kuntze, S. (2010). Zur Beschreibung von Kompetenzen des mathematischen Modellierens konkretisiert an inhaltlichen Leitideen. [Describing competencies of mathematical modeling with respect of core ideas in specific content domains]. MU, 56(4), 4-19.

Kuntze, S. (2013). Modellieren beim Nutzen von Darstellungen in statistischen Kontexten. In R. Borromeo Ferri, G. Greefrath \& G. Kaiser (Eds.), Mathematisches Modellieren in Schule und Hochschule (pp. 71-94). Wiesbaden: Springer Spektrum.

Kuntze, S., Aizikovitsh-Udi, E., \& Clarke, D. (2013). Strategies for evaluating claims-an aspect that links critical thinking and statistical thinking. In Lindmeier, A. \& Heinze, A. (Eds.). Proceedings of the 37th Conf. of the IGPME, Vol. 5 (p. 235). Kiel: PME.

Kuntze, S., Lindmeier, A. \& Reiss, K. (2008). "Using models and representations in statistical contexts" as a sub-competency of statistical literacy-Results from three empirical studies. Proceedings of ICME 11. [http://tsg.icme11.org/document/get/474].

Kuntze, S., Martignon, L., Vargas, F. \& Engel, J. (2015). Competencies in understanding statistical information in primary and secondary school levels. AIEM--Avances de Investigación en Educación Matemática, 7, 5-25.

Lipman, M. (1991). A Functional Definition of Critical Thinking. Thinking in education, 6, 114-125.

Lesh, R., Galbraith, P., Haines, C., \& Hurford, A. (Eds.). (2010). Modeling students' mathematical modeling competencies. New York: Springer. 
Maaß, K. (2006). What are modelling competencies? ZDM Mathematics Education, 38(2), 115-118.

Mayring, P. (2015). Qualitative Inhaltsanalyse. [Qualitative content analysis]. Weinheim: Beltz.

McPeck, J. (1981). The Meaning of Critical Thinking. Critical Thinking and Education, 1, 121.

Neubrand, J. (2002). Eine Klassifikation mathematischer Aufgaben zur Analyse von Unterrichtssituationen. Hildesheim: Franzbecker.

OECD. (2003). The PISA 2003 Assessment Framework. Retrieved January 20, 2007, from http://www.pisa.oecd.org/dataoecd/46/14/33694881.pdf

OECD. (2012), Education at a glance 2012: OECD Indicators. OECD Publishing. Retrieved October 12, 2016, from http://dx.doi.org/10.1787/eag-2012-en.

Reiss, K. \& Thomas, J. (2000). Wissenschaftliches Denken beim Beweisen in der Geometrie. Mathematica didactica, 23, 96 - 112.

Royalty, J. (1995). The generalizability of critical thinking: Paranormal beliefs versus statistical reasoning. The Journal of Genetic Psychology, 156(4), 477-488.

Schreier, M. (2012). Qualitative content analysis in practice. London: Sage.

Shaughnessy, J. M. (2007). Research on statistics learning and reasoning. In F. K. Lester (Ed.), The second handbook of research on mathematics teaching and learning (pp. 9571010). Charlotte, NC: Information Age Publishing.

Siegel, H. (1988). Educating reason: Rationality, critical thinking and education. New York: Routledge.

Thomas, J. (1997). Wissenschaftliches Denken im Jugendalter. Mainz: Universität.

Tschirigi, J. (1980). Sensible reasoning: A hypothesis about hypotheses. Child Development, 51, 1-10.

Watson, J.M. (1997). Assessing statistical thinking using the media, In I. Gal, \& J. Gar-field, (Eds.), The assessment challenge in statistics education (pp. 107-121). IOS Press.

Watson, J., \& Callingham, R. (2003). Statistical literacy: A complex hierarchical construct. Statistics Education Research Journal, 2(2), 3-46.

Weinert, F. (1996). Lerntheorien und Instruktionsmodelle. In F. Weinert (Ed.), Enzyklopädie der Psychologie. Vol. 2 (pp. 1-48). Göttingen: Hogrefe.

Weinert, F. (2001). Vergleichende Leistungsmessung in Schulen. In F. Weinert (Ed.), Leistungsmessungen in Schulen. (S. 17-31). Weinheim: Beltz.

Wild, C., \& Pfannkuch, M. (1999): Statistical thinking in empirical enquiry. International Statistical Review, 3, 223-266.

Willingham, D. (2007). Critical Thinking-Why is it so hard to teach? American Educator, 2007 (3), 8-19.

\section{CORRESPONDING AUTHOR}

Prof. Dr. Sebastian Kuntze

Ludwigsburg University of Education, Germany

Reuteallee 46, 71634 Ludwigsburg, Germany

kuntze@ph-ludwigsburg.de 


\section{University Library}

\section{- M M N E R VA A gateway to Melbourne's research publications}

Minerva Access is the Institutional Repository of The University of Melbourne

Author/s:

Kuntze, S;Aizikovitsh-Udi, E;Clarke, D

Title:

Hybrid task design: connecting learning opportunities related to critical thinking and statistical thinking

Date:

2017-11-01

Citation:

Kuntze, S., Aizikovitsh-Udi, E. \& Clarke, D. (2017). Hybrid task design: connecting learning opportunities related to critical thinking and statistical thinking. ZDM-MATHEMATICS EDUCATION, 49 (6), pp.923-935. https://doi.org/10.1007/s11858-017-0874-4.

Persistent Link:

http://hdl.handle.net/11343/282991 